\title{
Fertile Connections: Thinking Across Assisted Reproductive Technologies and Parenting Culture Studies
}

\begin{abstract}
Whilst studies of 'Parenting Culture' and 'Assisted Reproductive Technologies' (ARTs) are now well-established areas of social science scholarship, so far, the potential connections between the two fields have not been significantly explored. Responding to calls for a more 'processual' approach to studying reproduction (Almeling, 2015) in order to make clearer contributions to sociological theory more broadly, we begin a dialogue between these mutually relevant bodies of literature, highlighting connections and crosscutting findings. We focus on four interlinked themes - Reflexivity, Gender, Expertise and Stratification - and promote a more holistic approach to understanding how children are conceived and cared for within the current 'Euro-American' reproductive landscape. By way of conclusion, we draw attention to the contemporary context of 'anxious reproduction' and propose directions for future research.
\end{abstract}

Keywords: Parenting Culture, Assisted Reproduction, Gender, Expertise, Stratification

\section{Author names and affiliations}

Dr Charlotte Faircloth (University of Roehampton) and Dr Zeynep B. Gürtin (University of Cambridge)

\section{Corresponding author}

Charlotte Faircloth, Social Sciences, University of Roehampton, Roehampton Lane, London SW15 5SL, charlotte.faircloth@roehampton.ac.uk

\section{Main text}

\section{Introduction}

In her recent Annual Review of Sociology article, Almeling argues that reproduction, to date, has primarily been conceptualized as 'a series of events' (e.g. pregnancy, abortion, birth) that occur in women's bodies, with the consequence that the field has lacked 'a cohesive theoretical endeavor' and marginalized the experiences of men. Indeed, she notes, '[d]espite the ubiquity of this topic, sociological research on reproduction is considered a niche subfield located somewhere in the vicinity of gender and the family' (2015:424.) Instead, Almeling calls for a reconceptualization of reproduction as 'a multilayered biological and social process' in order to stimulate both theoretical and empirical developments in the field. Taking up her invitation to provide comparisons, not only across the life course and across reproductive 'events', but across different analytical levels, we develop a dialogue here between two significant and growing fields of reproduction research. The first is a nascent field of sociological and social policy scholarship that has been 
called 'Parenting Culture Studies' (e.g. Lee, Bristow, Faircloth and Macvarish 2014). The second, the burgeoning field of social and anthropological research concerned with the social, cultural and ethical aspects of the globalization of assisted reproductive technologies (ARTs) (e.g. Gurtin et al 2015). These two areas, whilst clearly having a lot in common in terms of their central focus on conceiving, raising and having children, have not - so far been brought into any sort of substantial conversation. It is our aim, (here and in recent activities elsewhere, Faircloth and Gurtin forthcoming, Gurtin and Faircloth forthcoming) to begin this exchange by mapping the common threads and overlaps, highlighting crosscutting findings, and indicating correlations and connections.

In line with Almeling's call, by seeking to understand reproductivity (including, in our case, the wide spectrum from reproductive imagining all the way to parenting), by developing an explicitly comparative framework, and by bringing men into the picture, we pick out some of the key insights from the growing sub-field of reproductive studies and position them in relation to broader sociological enquiry. This endeavor not only enables an appreciation of how much each sub-field has to contribute to understandings of the other, but also allows a clearer claim to be developed for the centrality of reproduction studies to sociological theory.

We briefly summarize the foci and findings of each of the two bodies of scholarship, before moving to the intersections between them across four interlinked themes. First, we discuss how normative and moralistic expectations around reproduction create individuals who need to be ever more reflexive and accountable for their reproductive actions and decisions. Second, we discuss how, despite a growing rhetoric of equality, the burden of reproduction continues to be heavily gendered (whether during ART treatment, 'natural" conception, childbirth, or everyday parenting), generating new kinds of tensions for 'egalitarian' couples in particular. Third, we draw attention to the growing role of expertise and closer monitoring and assessment of (intending) parents, with important implications for their sense of subjectivity. And finally, we look at the ways in which reproduction is both stratified to generate and exploit global inequalities, and segregated into camps and allegiances, which have a negative effect on wider social bonds. There are, of course, plenty of interrelated factors across these four themes, with issues around identity, choice, embodiment, relationships, equality and inequality creating overarching motifs.

Taken together, insights from parenting culture and studies of assisted reproduction provide a more holistic understanding of the lives of contemporary individuals, and add the much needed dimension of parentchild relationships as an antidote to the overwhelming focus of mainstream social theory on adult intimate relationships (cf. Bauman, 2003; Beck and Beck-Gernsheim, 1995, 2002; Giddens, 1991, 1992). We demonstrate the multiple ways in which men and women, parents, and intending parents, are faced with competing, and at times contradictory, discourses regarding not only how they should plan and execute their reproductive activities, but also how, to whom, and in what ways they need to account for these. We pinpoint 
greater anxiety - whether arising from fears around declining fertility or from not providing infants with optimal nutrition - as the unintended and paradoxical consequences of the (greater) availability of reproductive technologies and an increasingly 'intensive' parenting culture. By way of conclusion, we consider the negative implications of this contemporary context of 'anxious reproduction' on individuals, families, and broader society, and propose directions for future research.

Although the discussion we draw upon and contribute to engages with interdisciplinary research from multiple global locations, we are primarily focusing our analysis on the current 'Euro American' context, or what Strathern defines as 'the largely middle-class, North American/Northern European discourse of public and professional life' (1996:38). While we are mindful of the differences within and between 'Euro-American' settings (notably around access and the provision, or otherwise, of public services and benefits relating to reproductive health and childcare), and while we appreciate that this set of discourses is not necessarily confined to specific geographical or classed locales, we nevertheless acknowledge its hegemony on how a 'dominant' language of parenting and reproduction is formulated, particularly in global policy initiatives (Faircloth, Hoffman and Layne, 2013).

\section{Parenting Culture Studies}

Parenting has long been considered of great importance when it comes to the transmission of social norms and values, the continuation of kinship, family and household, and for reproducing local and national communities (Barlow and Chapin, 2010). Rather than focusing on 'relatedness', familiar to scholars of kinship (e.g. Carsten, 2000) however, recent sociological work has situated 'parenting' as critical for understanding contemporary changes in modern society - particularly in the US and the UK but also further afield (Faircloth, Hoffman and Layne, 2013). Drawing attention to broader socio-cultural processes that have cast modern child rearing as a highly important yet problematic sphere of social life, this work starts from the premise that raising children has become a more complex task than it used to be in the past. Far from simply ensuring the transition to adulthood, today's parents are expected to do much more to protect and optimise the development of their children (Lee et al., 2014). There are continuities with the past here, in that parenting has always been subject to moralizing and 'guidance', but the magnitude of the increase in expectations around raising children, particularly since the mid-1970s, (the fact that we even use the term 'parenting' as a verb at all) is striking: parenting classes, parenting manuals, parenting experts, and parenting 'interventions' are now so common-place as to be unremarkable (Lee et al., 2014).

Founded on a deterministic model of infant development, itself dependent on the birth of developmental psychology in the mid twentieth century, there is a widespread assumption that infant experience sets the blueprint for later life.

Parenting is therefore cast as the source of, and solution to, a whole range of problems - at both individual, and social levels (such as the 'obesity epidemic'). Rather than being something that is simple, straightforward or 
common sense, parenting is routinely presented as a task requiring expert guidance and supervision, particularly for those in lower socio-economic groups. Child rearing has become increasingly mediated through a cultural narrative that provides parents with rules - albeit sometimes ambiguous ones - about how to realize and develop skills in their roles as mothers and fathers. It is these rules that constitute 'parenting culture' (Lee et al., 2014). Of course, advice and guidance might well be useful and welcomed by parents, particularly as it relates to 'the basics' of childcare; here, however, we are interested in the implications of this expansion of 'parenting' into an expertisesaturated, policy-focussed and commercially fuelled area of social life.

Recognizing the gendered dimension to these changes, much work has drawn on the concept of 'intensive mothering' (Hays, 1996) in understanding the experiences of contemporary women, who are increasingly 'torn' between the spheres of work and home - as well as to theorise how and why certain everyday tasks of childrearing have become moralized sources of heated public debate (Faircloth, 2013; Hays, 1996; Lee et al., 2014). Arguing that the mother-child relationship represents a sacred bastion in a society otherwise governed by the pursuit of profit, Hays summarizes the characteristics of intensive motherhood, as 'child-centred, expert-guided, emotionally absorbing, labour intensive, and financially expensive ' (Hays, 1996: 8). Concurrently, over and above professional achievements, motherhood has increasingly been framed as one of, if not the most, fulfilling stages of the female lifecourse (Faircloth, 2013). Fathers have not been immune from this trend towards a more 'intensive' style of parenting, but it remains mothers to whom these cultural messages are largely targeted, and around women's reproductive choices that the fiercest debates reign.

The child-centered 'intensive' mother is one who is considered responsible for all aspects of her child's development - physical, social, emotional and cognitive - above and beyond anyone else, including the father (Hays, 1996:46). Ideally she demonstrates this commitment through embodied means, such as by breastfeeding, and no cost, physical or otherwise, is considered too great in her efforts to optimize her child (Wolf, 2011). As a body of work, Parenting Culture Studies therefore draws on important traditions within sociology around not only the 'doing' and 'display' of family (Finch, 2007) but also individualisation and risk-consciousness (Beck and Beck-Gernsheim, 1995, 2002). Indeed, one of the main features of this model, chiming with work done by modernization theorists (Beck, 1992; Giddens, 1999a) is the assumption that children are particularly vulnerable to risk in the early years and must be protected and catered to by their mother at all times, lest their development be compromised. In a 'neo-liberal' era, with its emphasis on self-management, 'good' mothers are reflexive, informed consumers, able to 'account' for their parenting strategies (Murphy, 2003). Arguably, children have become not only 'lifestyle projects' but also a site of women's 'identity-work' (Faircloth, 2013) whereby individuals, selfconsciously or otherwise, may come to be associated with various 'tribes' (e.g. 'attachment parents', 'Tiger moms' or 'Ferberisers').

Being an 'involved' mother means more than merely being available, as it did 
for the 1950s housewife. Today, child rearing has become a full-time activity about which mothers are expected to be highly informed and reflexive. In a period of 'intensive' parenting, permeated by processes of individualisation, parenting must continually be reflected upon and the individual is assigned responsibility for ensuring that his or her parenting is 'good enough'. Yet to be reflexive about knowledge is a largely middle-class concern (Strathern, 2005: 3 ), and the focus on intensive motherhood is to take a specifically middleclass perspective. Our argument here is that engagement with this framework of intensive mothering is valuable because it presents culturally dominant beliefs (Hays 1996). That is, the middle class presents the most powerful, visible and self-consciously articulated model readily apparent in public discourse and policy. Of course, the perception of what is a 'good parent' is largely culturally, historically and ideologically rooted, and thus in continuous change. So a 'middle class' or 'Euro-American' cultural script does not affect all parents in the same way around the world - class, ethnicity and gender all affect its internalization, and there may be a curious combination of adoption, resistance or adaptation according to specific time and place. What is important, nevertheless, is that this script is increasingly recognized by many parents the world over as the 'proper' way of parenting, an injunction to which they must respond (Arendell, 2000).

\section{Assisted Reproductive Technologies}

Although one of the most striking aspects of ARTs has been their rapid globalization, at least as interesting has been their 'localization' upon reaching various global destinations. During the decades since the birth of Louise Brown in 1978, not only in vitro fertilization (IVF), but also conception via the use of donor eggs, sperm or embryos, and surrogacy have all provided new means for individuals to become parents. More recently, the growth of egg freezing and the use of new genetic technologies, such as pre-implantation genetic screening (PGS), are expanding the field of medicalized reproduction even further, increasingly including the 'fertile' population. Adapted to aid the creation of what anthropologist Inhorn (2003) has termed 'local babies', these global technologies have led not only to the birth of over 5 million 'miracle babies' worldwide but also to significant culture change (Inhorn and Birenbaum-Carmeli, 2008). Moreover, while the regulation and framing of ARTs have diverged almost inexhaustibly in different jurisdictions (e.g. Ory et al., 2013), the experiences of women and men engaging with these technologies in varied locations have proven surprisingly similar (e.g. Inhorn, 2003; Franklin, 1997; Becker, 2000;).

It is not surprising that the growth and development of technologies that offer solutions to the age-old problem of infertility - promising to create babies, and also parents and families (Franklin, 1997; Strathern, 1992a, 1992b;

Thompson, 2005) - should have a significant impact, not just on the lives of involuntarily childless individuals, but on much more fundamental questions about reproduction, the meaning of kinship and the relationship between nature and culture or science and society. Strathern's book, Reproducing the Future (1992b) presciently articulated the cultural relevance of ARTs and the distinctions they enable between social and biological parents. Indeed, the 
'de-naturalization' of reproduction through the provision of technological 'assistance' - 'giving nature a helping hand' (Franklin, 1997, 2006) - and the potential for the fragmentation of parenthood through the involvement of thirdparties (e.g. egg, sperm and embryo donors or surrogates) in the reproductive process, has had both destabilising and generative impacts on notions of naturalness, relatedness, gender, embodiment, enterprise, choice, consumerism, medicalization, expertise and parenting.

In many contexts, and repeatedly over the past thirty years, the study of ARTs has highlighted the centrality of reproduction to life-course expectations and normative assumptions, as well as the perceived sense of chaos that arises when this expectation cannot be met (e.g. Sandelowski, 1993; Inhorn 2003). In light of this, involuntary childlessness and reproductive loss have often been conceptualized as major disruptions to life plans, gendered identity, and relationships: a crisis in need of resolution (Becker, 1999). The multiple and imaginative ways in which technology and 'assistance' can be normalized and naturalized when in the service of this resolution has also been an overarching finding (e.g. Thompson, 2005). Moreover, 'the desire to parent', itself naturalised by a variety of ideologies - whether predicated on the primacy of the parent (mother)-child bond, or referencing pronatalist concerns (Gurtin 2014) - has become the ultimate justification for the use and development of ARTs, as well as the fuel for their geographical and social spread. Increasingly, using both human rights and discrimination language, claims are being made to extend access to affordable ARTs in low-resource settings (Inhorn, 2015; Vayena et al., 2002) as well as to broaden access to enable the formation of various types of non-traditional families (Mamo, 2007). However, this general trend supporting greater access to ARTs and the formation of new family forms should not be confused with relaxed codes of conduct; on the contrary, just like parenting, we can argue that 'rules' - albeit sometimes ambiguous ones - based on various cultural scripts increasingly delineate the appropriate and inappropriate behaviours of 'intending-parents' seeking conception via ARTs. Thus, this rule-bound reproductive and parenting landscape is in many ways contrary to the increasingly fluid, creative and elective landscape of 'do-it-yourself' adult intimate relationships (cf. Bauman, 2003; Beck-Gernsheim, 1998; Giddens, 1992).

Although a couple's involuntary childlessness can be caused by a range of physiologically male and female factors, these underlying causes may not receive social acknowledgement, and globally the major burden and blame for infertility continues to fall mostly on women's shoulders (Inhorn and Birenbaum-Carmeli, 2008; Inhorn and Van Balen, 2002). Indeed, the scholarship on ARTs demonstrates the pervasively gendered nature of infertility, and these gendered asymmetries are exacerbated by women's attempts to disguise and 'take on' the infertility of their husbands (Inhorn and Van Balen, 2002). Moreover, when medical treatment is sought, women bear the physical brunt of treatment, regardless of the physiological causes of childlessness. Hence, although the increased use of ARTs is both facilitating and intersecting with changes to traditional patriarchal structures and childrearing practices, 'patriarchal paradoxes' continue to surround fertility treatment, particularly in certain cultures (Inhorn, 2003), and beg the question 
of how 'emotional democracy' (Giddens, 1999b) can exist in relationships that clearly seem to lack, what we might call, 'reproductive democracy'.

As well as being heavily gendered, another common finding regarding the experience of ARTs is just how taxing they can be on bodies and emotions. Often experienced as much more difficult than anticipated from the outside, and described variously as 'a maze' (Sandelowski, 1993) or 'a roller-coaster', IVF treatment can take over and become 'a way of life' (Franklin, 1997). Even in cases of poor prognosis or multiple failures, these technologies can make intending parents feel 'compelled to try' (Sandelowski, 1993) and to continue treatment with tenacity and hope, even as chances of success diminish. Valenced as they are towards repetition and catering to a captive market, ARTs constitute not just a medical or technological niche, but an ever-growing 'baby market' (Becker, 2000; Spar, 2006), particularly in contexts with little or inadequate public funding, such as the US. At the nexus of medicine and consumerism, ARTs proliferate choices for involuntarily childless couples and individuals, and create new cultural imperatives (Strathern, 1992b) mandating technological assistance, often making it ever harder to deny or stop 'treatment', regardless of how demanding it becomes. Indeed, it is striking that Hays' 'child-centred, expert-guided, emotionally absorbing, labour intensive, and financially expensive' (1996:8) characterization of intensive mothering could equally be a description of the experience of undergoing ARTs.

\section{Reflexivity}

The notion that having (biological) children is central to adult identity is not new, of course; but in an era of 'liquid love' (Bauman, 2003) kinship with a child has increasingly been cast as the only permanent, and therefore meaningful, relationship (Beck and Beck-Gernsheim, 1995). Whilst both parenting and reproduction are conducted by individuals within a broad social context, and with reference to a peer group, cohort, or community, decades of research has shown that these activities - or rather individuals' real or perceived successes and/or failures to fulfil them in the time and manner prescribed - can as often result in feelings of isolation, shame and disruption, as they can in feelings of inclusion. Reproduction, for many, becomes a pivotal aspect of their lives according to which they feel that they are valued or devalued members of society, 'fitting in' or being 'left out' of social relationships.

In a reproductive landscape that places such importance on parenting, 'accountability' might be said to be one of the growing requirements of reproductive agents. While both ARTs and a proliferation of child-rearing expertise might on the one hand be seen as expanding the choices available to individuals, on the other they simultaneously reinforce (hetero-)normative expectations around conception and parenting. Thus, whilst these technologies diversify family forms, by enabling same-sex couples to become parents (for example) (Golombok, 2015), rather than challenging the concept of the family, they in fact reinscribe a normative model of children being cared for by (where possible biological) parents in the private sphere, meshing with other forms of stratification (see below and also Allen and Taylor, 2012). 
Normative expectations require individuals to be able to reflexively explain and account for their choices (see Beck, 1995; Giddens, 1991), regarding not only the major decisions of why they are (or are not) becoming parents at a given time, but also the smaller decisions of which method of feeding or sleeping they have chosen.

It is our argument here that the scholarship on ARTs and parenting culture reveals reflexivity and accountability to be particularly prominent aspects of contemporary reproduction, a domain that is under heavy surveillance and (formal and informal) normative pressures. As other scholars have noted, the moralization of reproductive decisions in a risk-conscious, child-centred culture means parents' choices around making or raising their children have intersected with parental (and specifically maternal) identity in an unprecedented way (Faircloth, 2013; Murphy, 1999). In a culture where 'breast is best,' for example, Murphy's work with mothers who use formula milk in the early months addresses the moral work a woman has to undertake, if, as she puts it, she is to respond to the charge of being 'a 'poor mother' who places her own needs, preferences and convenience above her baby's welfare' (Murphy, 1999: 187-8). Wolf (2011) links this perceived sense of surveillance to the redefinition of dangers as 'risk', and talks about 'total' motherhood to characterize the experience of contemporary parents (again, specifically mothers) who must not only protect their children from immediate threats but are also expected to predict and prevent any circumstance that might interfere with putatively normal development' (Wolf, 2011, p. xv)

Work in reproductive sociology is demonstrating how these demands are increasingly true also for would-be parents. In seeking fertility treatment (which is necessarily instrumental), for example, couples are expected to account for (and embody) an intensive commitment to parenting before becoming parents: once they embark on a course of treatment, (potential) mothers and fathers must behave as (actual) mothers and fathers. Moreover, newer forms of ARTs - such as, for example, PGS and egg freezing - require that individuals (in addition to accounting for their reproductive decisions in the present), begin to act as reflexive, forward thinking, responsible reproducers far in advance of the time in which they actually intend to parent. These technologies prey on (and respond to) the anticipatory anxiety of men and women and create what we have termed 'pre-conception parents', in the same way that predictive (genetic) testing has created the 'pre-symptomatic ill person' (Konrad, 2003). As work around the intensification of parenting has argued more generally, this could be seen as an example of 'extending parenting culture backwards' (Lee et al., 2014), whereby the increasingly intensive requirements of pregnancy and parenting are assumed to be relevant even to the pre-conception period. This is particularly clear in the case of involuntarily childless intending parents who are explicitly required to jump through a series of hoops as they prove themselves deserving recipients of treatment, or adoption procedures, aligning themselves much more closely with the ideals of an intensive parenting culture than many actual parents do. Understood in this way, it becomes clear not only how ARTs extend parenting behaviour temporally backwards, but also demonstrate why many of the same concerns and rules that govern parenting 'culture' are also generating a 
'culture' of ART engagement. Whilst this helps to create many families that might not otherwise have existed, it often requires ever greater commitment to parenting norms from those intending parents, thereby intersecting with the forms of stratification we discuss below (see also Allen and Taylor, 2012).

\section{Gender}

It almost goes without saying that reproduction is gendered: if accounts of the development of an 'intensive parenting' culture have emphasized how it influences mothers in particular, literature on ARTs has consistently drawn attention to the unequal burden and embodied labour of women (e.g. Inhorn and Birenbaum-Carmeli, 2008). It is, however, striking that the demands placed on women in their role as mothers have intensified as they have continued to enter the labour market (rather than decrease, as one might expect). Partly as a means to counter this imbalance, which sees women working what Hochschild (2003) described as the 'double shift', EuroAmerican societies have witnessed the construction of the 'involved father' (Miller, 2011), facilitated by measures such as split parental leave or flexible working polices (in many North-European contexts at least; an important point of contrast with the US, where no such provision exists, even for maternity leave). Men are increasingly encouraged to be 'engaged' in childcare, with a particular emphasis on the importance of creating a close emotional connection with their children, in place of the more traditional model of the patriarchal breadwinner (Dermott, 2008; Faircloth 2014). Not surprisingly, then, accounts from sociologists reveal that fatherhood is also becoming more and more central to men's 'identity work' in their accounts of personal life. Yet whilst discursively fathers may be encouraged to be 'involved' in parenting and take more of an equal load of childcare, in reality, women who continue to shoulder most of the responsibility for this (Dermott, 2008; Faircloth 2014). It is women who typically take extended periods of time away from paid work, and move to part-time hours when they do return to the workplace, if they return at all. What is more, despite this emphasis on the importance of splitting responsibilities, optimal infant care as promoted in the current reproductive landscape is an inherently gendered, embodied one, often rationalized through an evolutionary, 'naturalizing' logic: women are strongly encouraged to breastfeed their babies by health professionals and policy makers, particularly in the early months, a practice which has a cascading impact on many other aspects of infant care (such as soothing and sleeping).

In studies of assisted reproduction, perhaps it is easier still to observe the inherent gendering of reproduction, since ARTs exaggerate and manipulate the gendered asymmetries of the reproductive process for heterosexual couples. Moreover, the physical requirements of IVF on female bodies are necessarily and correspondingly translated into more time spent at the clinic, increased interaction with medical professionals, and a need to audit one's own body and bodily changes, as well as the greater importance of monitoring one's psychology and emotions (not least since these, women are told, may effect 'treatment' outcome). While it is important not to overlook men's role in the fertility treatment process, which can also at times prove psychologically and physically demanding (Gurtin-Broadbent, 2009), scholars have noted that 
men are indeed 'the second sex' with respect to ARTs (Inhorn et al., 2009). These observed imbalances, both with regards to parenting and ARTs are all the more striking precisely because they are currently perpetuated in the shadows of an overt 'equality' or 'women's empowerment' rhetoric within Euro-America, which can have an ever more corrosive impact on couple equality. Clearly, having children or even trying to conceive them, as well as cementing adult relationships, also places new pressures on them. This is nothing new; what is new, however, is the ways this works itself out for contemporary couples who have been raised on a discourse of gender equality. In the case of parenting, for example, stresses emerge either because one parent feels unduly burdened with the task of care (typically, the woman) or because both parents are 'intensively' engaged in parenting and therefore 'torn' between the worlds of work and home. Certainly, for many couples, marriage during the early years of child-rearing becomes more akin to a 'shift-system' of care, than the more spontaneous or affect based relationship they were once familiar with (Author 1 ). Clearly this is affected by what sort of state support (if any) there is for extended parental leave, childcare and flexible working.

How, then, do couples deal with and 'account' for this inequality? Gender scholar Kandiyoti (1998) suggests that 'bargaining with patriarchy' involves the ways in which women strategize in order to optimise their security and life options within a given set of concrete patriarchal constraints; a theory that seems productively applicable to many reproductive scenarios. According to this theory, for example, women's self-ascription of their husbands' infertility (Gurtin, 2014) can be understood as a 'bargain' in exchange not only for the security of their marriage, but perhaps for a range of other desired outcomes, such as seeking medical treatment. Similarly, we might also understand young women's desires to freeze their eggs, thereby giving themselves a little more flexibility and maximising their options within the constraints of a broadly patriarchal society that makes their educational aspirations, workplaces, or personal circumstances incommensurate with the demands of biological reproductive aging. We might also, perhaps, see a form of patriarchal bargain in the choices of 'intensive mothers' who devote themselves to the nurture of their children in ways that necessarily require more investment from them than from their male partners, simultaneously providing value for the work that they are doing while limiting the scope of more egalitarian divisions of labour.

\section{Expertise}

Research around the medicalization of reproduction and parenting has long formed a cornerstone of feminist sociological and anthropological inquiry. Whilst the growth of reproductive expertise has had numerous benefits (childbirth is now far safer than ever, for example), Apple (1987) notes that the development of expert knowledge about parenting was intimately tied up with the rational-efficient management of birth and infant care, which became increasingly prevalent during the twentieth century. With the increasing hospitalization of childbirth, measurements concerning infant development were collected by medical staff and observed over time, leading to the calculation of norms. Measurements were taken under the auspices of 
enabling women to optimise their child's development; however, rather than simply describing the 'is' they also prescribed what 'ought' to be in the form of conscious or unconscious targets (Rose 1999). Images of normality generated by measurement and expertise therefore also came to serve as means for individuals to normalise and evaluate their own lives.

As Lee notes, '[t]he 'expert' is a key figure throughout the history of the modern family, indicating that the ability of the parent to raise the child in an effective way has been continually called into question.' (2014: 74). Certainly, the messages of experts, regarding what is wrong and what needs to change in the way children are raised, reflect the wider social and cultural context of the time, and this is not culturally or historically stable. However, many have noted that underlying the contemporary field of 'parenting expertise' is a deemphasis on the importance and value of 'instinct', at least when compared to the past; instead, effective parenting is seen as reliant on acquired or learned skills. Arguably even the most 'instinctive' element of the parenting relationship, love, has now been instrumentalised in the interests of optimizing outcomes (Rose, 1999).

Whilst professional oversight of pregnancy (and the period pre-conception) for all women (and now for would-be fathers) is increasingly extensive (Lee et al., 2014), it is evident that those who need assistance to conceive experience considerably more scrutiny than those who do not. More recently, however, what we have begun to see is both a temporal extension of the 'medical (or expert) gaze', back in time to pre-conception, and forwards all the way to the parenting of teenagers, and also its spatial extension from hospitals and clinics, into people's homes. Those seeking to make babies, particularly via ARTs, submit themselves not only to the medical expertise of doctors, but also to the advice of multiple experts on nutrition, exercise, and even stressmanagement. While experts inside fertility clinics manage the microscopic details of bringing reproductive cells together, those outside routinely intervene in the child-rearing practices of those considered in need of skilling up, especially within 'vulnerable' or 'hard to reach' groups, via various parenting 'classes' and guidelines (Gillies, 2009).

\section{Stratification}

Although both parenting cultures and ARTs are continually developing and changing, they do so within broader social and global relations, trends, and inequalities. As first introduced by Colen in her 1986 study of West Indian domestic workers and their employers in New York, and subsequently developed by Ginsburg and Rapp (1995), the term 'stratified reproduction' draws attention directly to these inequalities. Pointing to both the sexual politics and the political economy of reproduction, stratified reproduction as an analytic lens demands that we note the many explicit and implicit ways in which classed, raced, gendered, and placed hierarchies intersect with reproduction, meaning that some reproductive futures are valued and encouraged, while others are despised and discouraged.

The usefulness and applicability of stratified reproduction as a concept is 
evident not only in designations of 'good' parenthood, and the corresponding moral panics surrounding bad parents, but also in the legal, ethical and economic regulation of ARTs, which extend or curtail access according to similar designations. Even if legal and economic access to ARTs are granted, which remain significant barriers for many, intending parents must be deemed suitable applicants by clinicians who judge them on a range of factors framed around the 'welfare of the child' principle. Indeed, it is perhaps not surprising that those women, particularly from low-socioeconomic or minority groups, who have the least access to medically assisted reproduction are often the very same groups targeted by states or public health and education campaigns for the prevention of unintended pregnancies. ARTs predominantly assist the reproduction of privileged groups and remain far from the reach of most involuntarily childless. Moreover, as detailed in Bell's (2014) recent study of infertility in the US, class context mediates not only women's economic resources and access to reproductive care, but also their attitudes towards reproductive planning and control, meaning that experiences of infertility - including how and when it is recognized, and whether it is discussed with others - are also stratified along socio-economic lines.

From a broader, global, perspective, it becomes even more evident that, 'multiple sets of inequalities surface in the practice of assisted reproduction, reflecting intersecting oppressions' (Inhorn and Birenbaum-Carmeli, 2008:184). As well as denying or compromising access to ARTs to much of the world's involuntarily childless through a variety of structural, ideological, social relational, practical, and even biological 'arenas of constraint' (Inhorn, 2003), these oppressions also co-opt the (re)productive capacities of some (often from the global South) into the service of others (often in the global North). For example, the development of cross-border reproductive care and the increasing commercialization of reproductive 'assistance' within a globally stratified 'baby business' (Spar, 2006), has led to the emergence of various 'hubs' specialising in different reproductive services (Gurtin and Inhorn, 2011), with feminist scholars warning of new forms of 'eggsploitation' (Pfeffer, 2011) and questioning how to value the (re)productivity of women whose bodies are disaggregated in neo-liberal markets that trade without borders (Gupta and Richters, 2008). Despite the language of 'gifts' or 'sisterhood' (Teman, 2010; Pande, 2011), the globalisation of ARTs often reflect power and economic inequalities, creating 'not a newly flat world' (Franklin, 2011) but a traditionally stratified one (Inhorn and Gurtin, 2011), with globally disadvantaged women generating a pool of reproductive 'assistors' - be they nannies, domestic workers, egg donors or surrogates - for the use of those with global advantage. Public services relating to reproduction and childcare within local settings therefore affect the way in which individuals and couples navigate this terrain.

This sense of seemingly 'collaborative' reproduction might at first seem at odds with the social segregation of parenting noted by parenting culture scholars (Lee at al., 2014), away from a more collective model of care in the wider social network towards one prioritizing the importance of one-on-one care by a biological parent (typically, the mother). However, we argue that both these developments are a product of the same individualizing logic, 
underlying both reproductive technologies and the intensification of parenting, which reinforces feelings of segregation and isolation - whether between the parent and other adults, the generations, partners, or those that do and do not have access to various reproductive services. In fact, it is possible to argue that assisted reproductive technologies, by fragmenting the roles of parenthood, foster what might be the most individualising approach to reproduction imaginable, down to the level of gametes. In providing new ways to intensify the stratification of reproduction, whether through the creation of new relationships or the development of ever expanding forms of expertise that designate what is necessary for good parenting, both the globalization of ARTs and contemporary parenting culture produce segregated individuals, who not only have to account for their various reproductive choices by scrutinizing others, but are also required to reinforce the closeness of the parent-child tie even - especially - in a social context where social and familial bonds of solidarity are fragmenting.

\section{Concluding Comments}

Although traditionally distinct, studies of ARTs and parenting cultures serve as mutually informative sites by which to examine the different facets of reproduction in contemporary society. Following a review of the literature in both fields, we have focused on four interlinked themes - Reflexivity, Gender, Expertise, and Stratification - to demonstrate how a comparative approach can yield more holistic insights about the contemporary landscape of reproduction. We see each of these as central and definitive aspects of how reproduction is organised and experienced by women and men, parents and intending parents within and between Euro-American contexts, as well as critical themes for sociological theorisation.

As this article has demonstrated, the demands that are currently placed on parents and 'pre-conception parents' - regarding their own physiology, psychology and emotional welfare, as well as the responsibilities placed on them to ensure the physical, psychological, and emotional welfare of their current or future children - far exceeds anything that has come before, and might best be described as relentless. Moreover these relentless demands result in a temporally and spatially extended scrutiny - covering the fertility clinic, the home, and leisure activities from before a child has even been conceived well into its early adulthood. Indeed, the demands - including what one must eat or not eat, which medical regime to adopt, what games to play with your child, which nursery lists to enrol in, which extra curricular activities to partake in, and more - are never-ending; one can always be doing more and doing it better. Paradoxically, while both ARTs and parenting expertise aim to 'assist' reproductive agents in their conception and child-rearing endeavours, they also generate new choices, burdens, responsibilities and accountabilities. The result, unsurprisingly, is increasing anxiety for parents and intending parents. In this moment of 'anxious reproduction', despite diligence and the use of multiple resources, reproductive agents often end up feeling overwhelmed, scrutinized, and 'not good enough' parents. This not only resonates with work going on across the social sciences around the relationship between neoliberalism, economic crises, career precarity and 
individualisation more broadly, but should alert us to the unrealistic, and counterproductive, expectations currently placed on reproducing the next generation.

In thinking about how best to develop these findings, one dimension we consider is the ways in which members of a family are, implicitly, pitted against each other with ideologies that advocate for, for example, the welfare of the child, as if this can be defined and supported in isolation from the welfare of the child's parents. Hence, parents and intending parents, whether consciously or not, are expected to relegate their own desires and wellbeing to a position secondary to their (intended) child's. Instead, we would advocate for a more holistic approach that takes account of the members of a family as interconnected parts and would encourage discourse on the 'welfare-of-thefamily'. Moreover, at the level of the family, we are interested not just in the gendered or couple relationships between parents but also in the transformation of relations between generations. Scholars working on parenting culture in the UK have observed that one of the negative effects of a more intensive, expert-driven individualising approach to parenting is the impact on intergenerational relationships (Lee et al., 2014). Where tacit authority was less contested in the passage from one generation to the next, contemporary, expert-based parenting culture has magnified a disruption to this cultural transmission, as grandparents or the older generation are not considered well informed enough to take care of children. (A problem undoubtedly exacerbated by trends towards delayed parenthood -meaning longer gaps between generations - and more geographically dispersed family units). Where parents (or, mothers) are understood to be the only ones capable of caring for their own children, everyone else is treated with suspicion (grandmothers and fathers, as much as other relatives or childcare workers). It is ironic, then, that intensive parenting, with the optimally developed child at the centre, aims to bring about stronger social ties, because in fact the ethos can pit members of a community against each other. Reproductive practices operate as a particularly moralised barometer of this antagonism: This landscape has created a situation where parents feel less certain of their ability to turn to others for support in the general business of raising children. Instead, the 'tribe' that does it 'right' is pushed further inward, away from society, identifying others 'out there' not as partners in a shared endeavour of community building, but as victims in need of education (Faircloth, 2013). Arguably, these trends in the reproductive landscape (especially in settings where the state or employers offer support for parents) have led to an ever-greater segregation not only between parents stratified along socio-economic, educational, and race lines, but also between parents and non-parents, particularly in the work place. In the UK, for example, greater entitlements for parents(in terms of sick leave, holidays and flexible working) has been shown to be a source of resentment for childfree colleagues, particularly where having children is understood as merely a 'lifestyle choice' (Bristow 2014).

A further direction for development is to better understand the changing patterns of social reproduction, with shifts from natural generational reproduction to a more bureaucratised, planned, and reflexive process, 
whereby mothering (or parenting) changes from a 'natural' or 'innate' to an achieved status. One of the downsides of the availability of reproductive technologies might be that there has actually been a questioning of 'natural' parenthood: as scholars working on parenting culture have observed, 'natural' pregnancies are becoming increasingly problematized, just as those who do not have 'training' for parenting are considered in need of 'skilling up' (the stringent tests and training faced by those who wish to adopt is salutary here, see De Graeve and Longman 2013).

Finally, and broadening out even further, we advocate critical thinking about the wider social debates and dynamics around our contemporary culture of reproduction. What does the technologization of reproduction do for society, in terms of our thinking about where children come from (a question Strathern judiciously drew our attention to in After Nature, 1992a)? What is our collective responsibility for the care of a new generation? To what extent do the ideologies of intensive parenting and the technologies of assisted reproduction (particularly, for example, in the case of transnational gamete donation and surrogacy) require the perpetuation or creation of inequalities and stratifications - be they at the global or familial level - in ways that do - or should - make us uncomfortable? Our argument is that only by bringing work on assisted reproduction and parenting culture together, and bridging the dominant distinction between work that focuses on how 'children come to be' and 'how children are cared for once they exist' (cf. Almeling, 2015: 424), can the inter-dependence and mutual construction of ideas, ideals and expectations regarding the bearing and rearing of the next generation be fully understood. 


\section{Acknowledgements}

We would like to thank the participants at our two 'Making Parents' events - at the American Anthropological Association Annual Meeting in 2015, and at the British Sociological Association's Human Reproduction and Families and Relationships Study Groups joint meeting held at the University of Roehampton in December 2015 - during which we first raised and explored many of the ideas that inform this paper. Thanks also to the anonymous reviewers, members of the Beaver Hall Reading Group, Dr Nicky Hudson, Anna-Helga Horrox, Helen Shariatmadari, and particularly Professor Wendy Sigle, for their engaged and constructive comments on earlier versions.

\section{References}

Allen, K. and Taylor, Y. 2012. 'Placed Parenting, locating unrest: failed femininities, troubled mothers and rioting subjects' Studies in the Maternal $4(2)$

Almeling, R. 2015. Reproduction. Annual Review of Sociology. 41: 423-42.

Apple, R. 1987. Mothers and Medicine: A Social History of Infant Feeding 1890

1950. Madison, WI: University of Wisconsin Press.

Arendell, T. 2000. 'Conceiving and Investigating Motherhood: The Decade's Scholarship', Journal of Marriage and the Family 62 (November):1192-1207.

Barlow, K. and Chapin, B.L. 2010. 'The practices of Mothering: An Introduction', in Journal of the Society for Psychological Anthropology, ETHOS, 38(4): 324-338

Bauman, Z. 2003. Liquid Love: On the Frailty of Human Bonds. Cambridge: Polity Press.

Beck, U. 1992. Risk Society: Towards a New Modernity. New Delhi: Sage

Beck, U. and Beck-Gernsheim, E. 1995. The Normal Chaos of Love. Oxford: Polity Press.

Beck, U. and Beck-Gernsheim, E. 2002. Individualization. London: Sage.

Becker, G. 2000. The Elusive Embryo: How Men and Women Approach New Reproductive Technologies. Berkeley, CA: University of California Press.

Becker, G. 1999. Disrupted Lives: How People Create Meaning in a Chaotic World. Berkeley, CA: University of California Press.

Bell, A. V. 2014. Misconception: Social Class and Infertility in America. New Brunswick, NJ: Rutgers University Press. 
Bristow, J. 2014. 'Who cares for children? The problem of intergenerational contact' in Lee, E. et al. 2014 Parenting Culture Studies Basingstoke and New York: Palgrave Macmillan.

Carsten, J., (Ed.) 2000. Cultures of Relatedness: New Approaches to the Study of Kinship. Cambridge: Cambridge University Press.

Colen, S. 1986. 'With Respect and Feelings': Voices of West Indian Child Care and Domestic Workers in New York City. All American Women: Lives That Divide, Ties that Bind, ed. Cole, J. New York: Free Press.

De Graeve, K. and Longman, C. 'Intensive mothering of Ethiopian adoptive children in Flanders, Belgium' in Hoffman, D and Layne, L. (Eds.) 2013.

Parenting in Global Perspective: Negotiating ideologies of kinship, self and politics. London: Routledge

Dermott, E. 2008. Intimate Fatherhood: A Sociological Analysis London: Routledge.

Faircloth, C. 2013. Militant Lactivism? Attachment Parenting and Intensive Motherhood in the UK and France Oxford and New York: Berghahn Books

Faircloth, C. Hoffman, D. and Layne, L. (Eds.) 2013. Parenting in Global Perspective: Negotiating ideologies of kinship, self and politics. London: Routledge.

Faircloth, C. 2014. 'Intensive fatherhood?' The (un)involved father' in Lee, E. Bristow, J. Faircloth, C. and Macvarish, J. Parenting Culture Studies Basingstoke and New York: Palgrave Macmillan. Pp 184-200

Faircloth, C. 2015. 'Negotiating intimacy, equality and sexuality in the transition to parenthood' in in Faircloth, C. and Twamley, K. Sociological Research Online Gender, intimacy and equality: Uncomfortable bedfellows? SRO Special Section, November.

Faircloth, C. and Gürtin, Z.B. (Eds). Forthcoming, Sociological Research Online special section 'Making Parents: Reproductive Technologies and Parenting Culture Across Borders'

Finch, J. 2007. 'Displaying Families.' Sociology vol. 41 no. 165-81.

Franklin, S. 1997. Embodied Progress: A Cultural Account of Assisted Conception. London: Routledge.

Franklin, S. 2006. 'Origin stories revisited: IVF as an anthropological project'. Culture, Medicine and Psychiatry, 30, 547-555.

Franklin, S. 2011. 'Not a Flat World: the future of cross-border reproductive care' Reproductive Biomedicine Online 23:7:814-816. 
Giddens, A. 1999a. 'Risk and Responsibility', in Modern Law Review, 62 (1): 1-10

Giddens, A. 1999b. Runaway World: How Globalisation is Reshaping our Lives. London: Profile Books.

Giddens, A. 1992. The Transformation of Intimacy. Cambridge: Polity Press.

Giddens, A. 1991. Modernity and Self-Identity: Self and Society in the Late Modern Age. Cambridge: Polity.

Gillies, V. 2009. 'Understandings and experiences of involved fathering in the United Kingdom: exploring classed dimensions', The Annals of the American Academy of Political and Social Science, 624, 49-60

Ginsburg, F. D. \& Rapp, R. (Eds.) 1995. Conceiving the New World Order: The Global Politics of Reproduction. Berkeley, CA: University of California Press.

Golombok, S. 2015. Modern Families: Parents and Children in New Family Forms. Cambridge: Cambridge University Press.

Gupta, J. A. and Richters, A. 2008. 'Embodied Subjects and Fragmented Objects: Women's Bodies, Assisted Reproduction Technologies and the Right to Self-Determination' Bioethical Enquiry 5 (4) pp 239-249

Gürtin-Broadbent, Z. 2009. "Anything to become a mother": Migrant Turkish Women's Experiences of Involuntary Childlessness and Assisted Reproductive Technologies in London.' In Culley, L, Hudson, N \& van Rooij, F. (eds) Marginalised Reproduction: Ethnicity Infertility and Reproductive Technologies. Earthscan.

Gürtin, Z.B. and Inhorn, M.C. 2011. Guest Editorial - Cross-Border Reproductive Care: Travelling for Conception and the Global ART Market. Reproductive Biomedicine Online, 23: 535-537.

Gürtin, Z.B. 2014. Assumed, promised, forbidden: infertility, IVF and fatherhood in Turkey. In M.C. Inhorn, W. Chavkin \& Navarro, J. (eds.) Globalized Fatherhood. New York, New York: Berghahn.

Gürtin, Z.B., Inhorn M.C., and Tremayne S. 2015. Islam and Assisted Reproduction in the Middle East: Comparing 'Secular' Turkey, Shia Iran, and the Sunni Arab World. In S. D. Brunn (ed.) The Changing World Religion Map: Sacred Places, Identities, Practices and Politics. New York: Springer

Gürtin, Z.B. and Faircloth, C. (Eds.) Forthcoming 'Conceiving Parenthood: Intentions, Expectations and Reproductive Assistance' Anthropology and Medicine special issue. 
Hays, S. 1996. The Cultural Contradictions of Motherhood . New Haven, CT, and London: Yale University Press.

Hochschild, A. 2003. The commercialization of intimate life: notes from home and work. Berkeley: University of California Press.

Inhorn, M.C. 2015. Cosmopolitan Conceptions: IVF Sojourns in Global Dubai. Duurham NC: Duke University Press.

Inhorn, M.C. 2003. Local Babies, Global Science: Gender, Religion, and In Vitro Fertilization in Egypt. New York, NY: Routledge.

Inhorn, M.C. \& Birenbaum-Carmeli, D. 2008. 'Assisted reproductive technologies and culture change'. Annual Review of Anthropology, 37, 177196.

Inhorn, M.C. and Gürtin, Z.B. 2011. Cross-Border Reproductive Care: A Future Research Agenda. Reproductive Biomedicine Online, 23: 665-676.

Inhorn, M C., and van Balen, eds, F. 2002. Infertility Around the Globe: New Thinking on Childlessness, Gender, and Reproductive Technologies.

Berkeley: University of California Press.

Kandiyoti, D. 1988. Bargaining with patriarchy. Gender and Society, 2(3), 274-290.

Konrad, M. 2003 'Predictive genetic testing and the making of the presymptomatic person: Prognostic moralities amongst Huntington's-affected families'. Anthropology \& Medicine, 10(1): 23-49.

Lee, E. et al. 2014 Parenting Culture Studies Basingstoke and New York: Palgrave Macmillan.

Mamo, L. 2007. Queering Reproduction: Achieving Pregnancy in the Age of Technoscience. Durham: Duke University Press.

Miller, T. 2011. Making Sense of Fatherhood. Cambridge: Cambridge University Press.

Murphy, E. 1999. "Breast Is Best': Infant Feeding Decisions and Maternal Deviance', Sociology of Health and Illness 21(2): 187-208.

Murphy, E. 2003. 'Expertise and Forms of Knowledge in the Government of Families', Sociological Review 51(4): 433-462.

Ory, S., Devroey,P., Banker, M., Brinsden, P., Buster, J., Fiadjoe, M. et al. 2013. IFFS surveillance 2013. International Federation of Fertility Societies.

Pande, A. 2011. 'Transnational Commercial Surrogacy in India: Gifts for Global Sisters?' Reproductive Biomedicine Online 23(5): 613-25. 
Pfeffer, N. 2011. 'Eggs-ploiting Women: A Critical Feminist Analysis of the Different Principles in Transplant and Fertility Tourism'. Reproductive BioMedicine Online, vol. 23(5): 634-661.

Rose, N. 1999 [1989]. Governing the Soul: The Shaping of the Private Self. London: Routledge.

Sandelowski, M. 1993. With Child In Mind: Studies of the Personal Encounter with Infertility. Philadelphia, PA: University of Pennsylvania Press.

Spar, D. L. 2006. The Baby Business: How Money, Science and Politics Drive the Commerce of Conception. Boston, MA: Harvard Business School Press.

Strathern, M. 1992a. After Nature: Kinship in the Late Twentieth Century. Cambridge: Cambridge University Press.

Strathern, M. 1992b. Reproducing the Future: Anthropology, Kinship and the New Reproductive Technologies. Manchester: Manchester University Press.

Strathern, M. 2005. Kinship, Law and the Unexpected: Relatives are Always a Surprise. Cambridge: Cambridge University Press.

Teman, E. 2010. Birthing a Mother: The Surrogate Body and the Pregnant Self. Berkeley: University of California Press.

Thompson, C. 2005. Making Parents: The Ontological Choreography of Reproductive Technologies. Cambridge, MA: MIT Press.

Vayena, E., Rowe, P. J. \& Peterson, H. B. 2002. 'Assisted reproductive technology in the developing world: why should we care?' Fertility and Sterility, 78(1), 13-15.

Wolf, J. 2011. Is Breast Best? Taking on the breastfeeding experts and the new high stakes of motherhood New York: New York University Press.

\section{Author biographies}

Dr Charlotte Faircloth is a Senior Lecturer in the Department of Social Sciences at the University of Roehampton, London. She is also a founding member of the Centre for Parenting Culture Studies (CPCS) at the University of Kent, and an Associate of the Reproductive Sociology Research Group (ReproSoc) at the University of Cambridge.

Dr Zeynep Gurtin is a Research Associate in the Reproductive Studies Research Group (ReproSoc) and Affiliated Lecturer in the Sociology Department at the University of Cambridge. Her work on this project was supported by the Wellcome Trust, grant number 100606. 